DOI: https://doi.org/10.24867/05BE11Jankovic

\title{
UTICAJ PROPADA NAPONA NA RAD PUNIONICA ZA ELEKTRIČNA VOZILA NAPAJANIH IZ SISTEMA KROVNIH FN ELEKTRANA
}

\section{THE EFFECTS OF VOLTAGE DIPS ON ELECTRIC VEHICLES CHARGING STATIONS POWERED BY ROOFTOP PV SYSTEMS}

\author{
Jovana Janković, Vladimir Katić, Fakultet tehničkih nauka, Novi Sad, Srbija
}

\section{Oblast - ELEKTROTEHNIKA I RAČUNARSTVO}

Kratak sadržaj - U ovom radu iznet je predlog realizacije postavljanja javnih punjača za električne automobile na teritoriji Grbavice (Novog Sada). Navedeni su osnovni problemi sa kojima se ova industrija danas susreće. Opisan je električni automobil, opisana je postavka stavljanja FN elektrana, kao i njihova podela prema tipu $i$ snazi. Prikazana je infrastruktura javnih punjača kao i predlozi postavke punjča na 7 lokacija. Dat je i proračun na osnovu kojeg je izvršen odabir opreme za napajanje $i$ zaštitu, kao i simulacija kratkog spoja u DigSilent-u.

Ključne reči: Električni automobili, FN elektrane, punjači, pad napona, DigSilent

Abstract - This paper outlines a proposal of setting up of public chargers for electrical vehicles in the territory of Grbavica in Novi Sad is presented. The main problems that the electric vehicle industry is facing nowadays are introduced.The method of setting of rooftop PV systemare represented in this paper as well as their division by type and power is described. The public charging infrastructure is presented and charger setting at 7 locations. There is also a budget based on which the power and protection equipment has been selected as well as simulation in DigSilent for short circuit.

Keywords: Electric cars, rooftop PV system, chargers, voltage drop, DigSilent

\section{UVOD}

Veliku emisiju štetnih gasova, a pogotovu gasova staklene bašte (GSB) izazvala je ubzanaindustrijalizacija, a naročito intenzivna motorizacija tokom XIX i XX veka. Danas se emisija štetnih gasova, koja potiče od vozila sa SUS motorom smatra jednim od najvećih ekološkim problema. Ovakav tip vozila predstavlja osnov modernog saobraćaja, a njihov broj i dalje brzo raste doprinoseći sve prisutnijim klimatskim promenama. U tom smislu, traže se adekvatna rešenja, koja će problem minimizovati ili potpuno eliminisati.

Jedna od mogućih alternativa jeste korišćenje automobila na električni pogon. Razvojem energetske elektronike i usavršavanjem baterija, upravljanje ovim automobilima i njihove performance postaju sve bolje.

\section{NAPOMENA:}

Ovaj rad proistekao je iz master rada čiji mentor je bio dr Vladimir Katić, red. prof.
Pored toga, energetska efikasnost električnih automobila je neuporedivo veća od automobila sa SUS motorima. Za njihovo napajanje razvijeni su posebni uređaji koji služe za punjenje baterija automobila, tzv. punjači. Grupisanjem punjača razvijeni su novi infrastrukturni elementi, javne stanice za punjenje. Najčešće se baterije pune koristeći energiju uzetu iz distributivne električne mreže, prethodno prilagođenu upotrebom pretvarača energetske elektronike. Da bi bio eliminisan uticaj na emisiju GSB, razmatraju se opcije sa korišćenjem obnovljivih izvora. Međutim, tada je proces punjenja osetljiv na razne poremećaje, od kojih su kvarovi u mreži, odnosno nestabilnost napona, pojava propada napona i sl. najverovatniji.

U ovom radu je predloženo rešenjeinfrastrukture punionica za električna vozila zasnovano na krovnim fotonaponskim (FN) elektranama u delu Novog Sada, koji se zove Grbavica. Na demo primeru, koristeći napredan softverski alat DigSilent, razmatran je i uticaj kvarova u mreži na njihov rad.

\section{ELEKTRIČNI AUTOMOBIL}

Pogonski sklop električnog automobila čini električni sistem (baterija,elektromotor i uređaji energetske elektronike) i mehanički sistem, koji električnu energiju prenosi na točkove. Osnovne prednosti električinih automobila su veća energetska efikasnot, jednostavna konstrukcija pogonskog sklopa, nizak nivo buke, i jednostavno upravljanje motorom. Međutim, postoje i nedostaci, kao što su nešto lošije vozne karakteristike u smislu manjeg radijusa kretanja, relativno niže konačne rzine, velika težina i gabariti baterija. Takođe, tu je i ekonomski elemenat, još uvek visoka cena.

Međutim, oni na indirektan način mogu doprineti većoj emisiji GSB, ako je električna energija, kojom se pune baterije, proizvedena u termoelektrani (TE) tj. iz uglja. $\mathrm{U}$ zavisnosti od tehnologije i efikasnosti rada, TE u atmosferu izbaci između $690 \quad \mathrm{gCO}_{2} / \mathrm{kWh}_{\mathrm{e}}$ i 990 $\mathrm{gCO}_{2} / \mathrm{kWh}_{\mathrm{e}}$ [1]. Električni automobili, koji se danas koriste, u proseku troše između $0,17 \mathrm{kWh} / \mathrm{km}$ i 0,2 $\mathrm{kWh} / \mathrm{km}$ [2]. Ako se uzme u obzir da su gubici u prenosnoj mreži oko $10 \%$, lako se dolazi do podatka da se prilikom vožnje potroši energija za čiju proizvodnju TE u atmosferu izbaci između $129 \mathrm{gCO}_{2} / \mathrm{km}$ i 218 $\mathrm{gCO}_{2} / \mathrm{km}$. Iako je to oko $10-15$ puta manje nego što iznosi emisija GSB SUS vozila, moguća je dalja redukcija, ako bi se baterije električnih automobila punili energijom iz FN elektrana. 


\section{KROVNE FN ELEKTRANE NA GRBAVICI}

Za napajanje električnih automobila iz krovnih FN elektrana razmotren je deo rada Novog Sada, Grbavica. Ovaj kvart karakteriše gusta naseljenost, veliki broj različitih stambenih zgrada i kuća, koje imaju različite oblike krovnih površina. Na slici 1 prikazan je satelitski snimak dela Grbavice sa jasno ucrtanim tipovima zgrada na osnovu krovne konstrukcije. Sa brojem 1 su označene zgrade sa kosim krovom, sa brojem 2 su označene kuće sa kosim krovom, a sa brojem 3 škole i zgrade sa ravnim krovovima. Kuće i zgrade sa kosim krovovima (1 i 2) razlikuju se jedni od drugih.

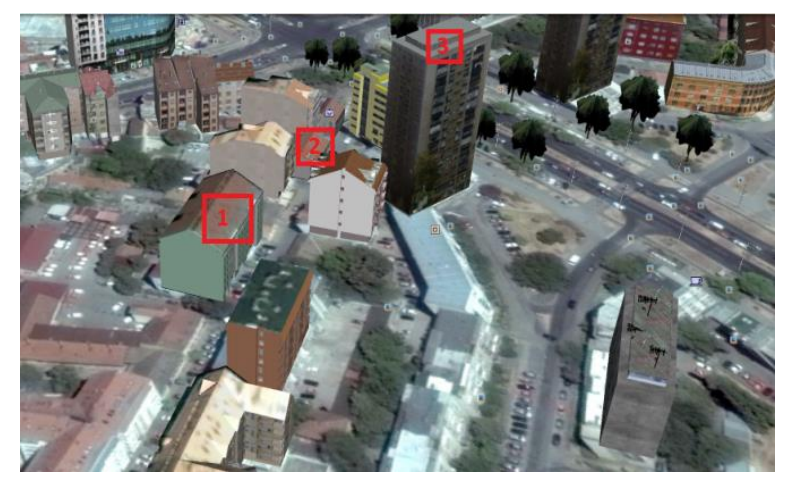

Slika 1. Određivanje tipskih krovova na Grbavici [3].

$\mathrm{Na}$ slici 2 prikazan je satelitski snimak kompletne Grbavice sa ucrtanim i pobrojanim različitim tipovima objekta na osnovu njihove krovne konstrukcije, za procenu krovne površine i njihovo grupisanje u tipske FN elektrane. Na bazi ovog pregleda mogu se postaviti (razlikovati) 4 tipa FN elektrana: 1. Na objekte sa kosim krovom sa solidnom orjentacijom jug-istok(crvena boja, ima ih oko 170); 2. Na objekte sa kosim krovom orjentisane većinom ka jugu (zelena boja, ima ih oko 64); 3. Na objekte sa ravnim krvovom (plava boja, oko 17); 4. Na objekte sa ravnim krovom, koji imaju na sebi elemente koji prave senku kao što su antene, dimnjaci, gromobrani i dr.(žuta boja, oko 11) [3].



Slika 2. Pregled tipskih krovova na Grbavici [3].

Za elektranu tipa 1 prosečna dnevna proizvodnja električne energije $34,1 \mathrm{kWh}$, dok je prosečna mesečna proizvodnja električne energije $1.040 \mathrm{kWh}$. Ukupna godišnja proizvedena snaga iznosi $12.500 \mathrm{kWh}$ [3].

Za potrebe tipa 2 može se zaključiti da je prosečna dnevna proizvodnja električne energije iznosi $10,8 \mathrm{kWh}$, prosečna mesečna $328 \mathrm{kWh}$, dokukupna godišnja iznosi $3.930 \mathrm{kWh}[3]$.
Za potrebe tipa 3 zaključeni su prosečna dnevna proizvodnja električne energije $94,3 \mathrm{kWh}$, dok je prosečna mesečna proizvodnja električne energije 2.870 kWh. Ukupna godišnja proizvedena snaga iznosi 34.400 $\mathrm{kWh}$ [3].

Za potrebe tipa 4 može se zaključiti da je prosečna dnevna proizvodnja električne energije $73,6 \mathrm{kWh}$, dok je prosečna mesečna proizvodnja električne energije 2.240 kWh. Na osnovu razmatranja došlo se do podatka da je na godišnjem nivou naša elektrana proizvela 26.900 $\mathrm{kWh}$ [3].

Izgradnjom FN elektrana na krovovima zgrada Grbavice pokrilo bi se oko $36 \%$ potrošnje električne energije. Ovo je okvirna vrednost, s obzirom na mogućnost određene greške zbog neophodnih pretpostavki i aproksimacija koje su učinjene. U najgorem slučaju, procena je da bi se obezbedila ušteda od oko $26 \%$, što je odličan rezultat rasterećenja elektroenergetskog sistema.

\section{POVEZIVANJE FN ELEKTRANA NA MREŽU}

Dalje pitanje je mogućnost priključenja ovih FN elektrana na mrežu radi plasmana generisane energije. U saradnji sa inženjerima iz Elektrovojvodine, predložena su najpogodnija mesta za priključenje četiri tipa FN elektrana. Za prvi tip elektrane (zgrade sa kosim krovom) predviđeno je priključenje na novu TS u ulici Miše Dimitrijevića 9A. Za drugi tip elektrana (kuće sa kosim krovom) moguće je priključenje na TS u ulici Doža Đerđa 50, za treći tip elektrne (zgrade sa ravnim krovovima) na TS u ulici Alekse Šantić 27, kao i četvrti tip elektrane. Na slici 3 su označene (uokvirene belim) opisane TS.
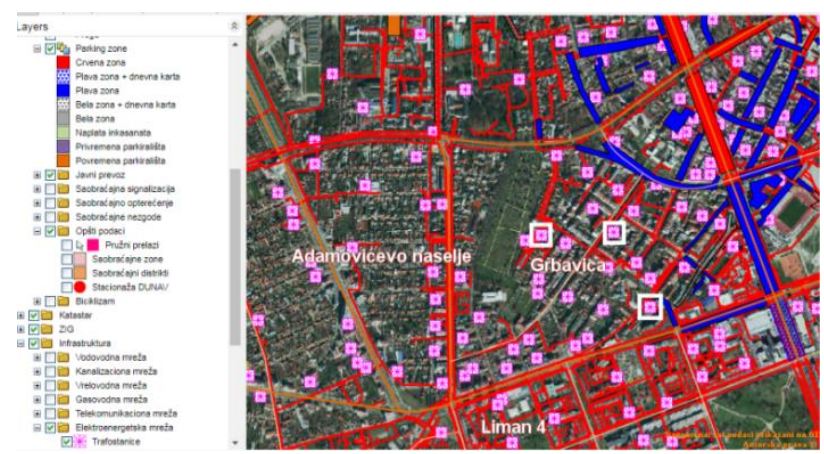

Slika 3. Prikaz TS za FN elektrane na Grbavici [3].

\section{INFRASTRUKTURA JAVNIH PUNJAČA}

Infrastrukturni element, koji služi za napajanje javnih punjača električnih automobila predstavlja stanica za punjenje električnih automobila ili punionica.

Na Grbavici, javni punjači (punionice) mogu se postaviti na različita mesta, na primer u okviru stambenog prostora (ukoliko ima parkinga),na taksi stajalištima ili javnim parkiralištima. Takođe postoji mogućnost instaliranja u okviru benzinskih stanica. Pored raspoloživog parking prostora, kriterijum za njihovo postavljanje je i da koriste postojeću električnu mrežu za svoje napajanje ili obnovljive izvore. Jedan od izazova za takvu infrastrukturu je nivo potražnje, vreme punjenja i način obračuna isporučene energije. Kod planiranja postavljanja javnih punjača na teritoriji Grbavice, mora 
se napraviti strategija po kojoj će biti izvršena podela zona, zatim optimalan broj punjača, kao i opravdanost postavljanja na određenoj lokaciji.

Za javne punjače izabrani su modeli kompanije ABB i to isključivo polubrzi i brzi punjači [4]. Korišćeni model za brzo punjenje je tipa AC, snaga $43 \mathrm{~kW}$, Terra 53 CJG, dok je model za polubrzo punjenjetipa AC, snaga 22 kW, Terra 23 CT.

Kod postavke punionica mora se voditi računa i o ukupnoj instalisanoj snazi, koja koja mora da odgovara kapacitetima distributivne mreže. Kako bi se opterećenje mreže usled novih priključenih potrošača (javnih punjača) optimalno raspodelilo, sve zone će biti povezane na posebne transformatorske stanice (ukoliko je to moguće), a instalisana snaga nijedne zone ne sme preći $130 \mathrm{~kW}$ (3 brza punjača). Nakon što je izvršen plan i raspored zona, izvršeno je pozicioniranje punjača i određena je napajačka transformatorska stanica za svaku zonu. Planirano je ukupno 7 lokacija za postavljanje punjača (L1-L7), a njihov pregled dat je u tabeli 1 . Predviđeno je postavljanje 6 brzih i 7 polubrzih punjača, ukupne instalisane snage od $412 \mathrm{~kW}$. U nastavku su dati detalji svake lokacije:

L1-Ulica Bulevar Oslobođenja 98 sa dvorišne strane. Dužina kabela je $80 \mathrm{~m}$ i TS se nalazi u dvorištu.

L2-Ulica Vladimira Nikolića 12. Dužina kabela je 53 m, priključuje se na istu TS kao i L1.

L3-Ulica Milana Simovića 8. Dužina kabela je $33 \mathrm{~m}$ a između uređaja $5 \mathrm{~m}$. TS je u dvorištu iza zgrade.

L4-Ulica Miše Dimitrijevića 30. Dužina kabela je 190 m, priključuje se na TS u ulici Miše Dimitrijevića 9A, kao i FN elektrana.

L5-Ulica Braće Ribnikar 4. Dužina kabela je 20 m, a između uređaja $5 \mathrm{~m}$. TS je u dvorištu zgrade.

L6-Ulica Bulevar oslobođenja 76. Dužina kabela je 80 $\mathrm{m}$, a između uređaja je $5 \mathrm{~m}$. TS je sa dvorišne strane.

L7-Ulica Alekse Šantića 57. Dužina kabela je 85 m, a između uređaja 5 m. TS je u ulici Alekse Šantića 26, gde je priključena FN elektrana.

Tabela1. Pregled svih lokacija i njihovih snaga

\begin{tabular}{|cccc|}
\hline Položaj & $\begin{array}{c}\text { Brzo } \\
\text { punjenje }\end{array}$ & $\begin{array}{c}\text { Polubrzo } \\
\text { punjenje }\end{array}$ & $\begin{array}{c}\text { Snaga } \\
{[\mathrm{kW}]}\end{array}$ \\
\hline L1 & 1 & - & 43 \\
\hline L2 & 1 & - & 43 \\
\hline L3 & 1 & 1 & 65 \\
\hline L4 & - & 1 & 22 \\
\hline L5 & 1 & 1 & 65 \\
\hline L6 & 1 & 2 & 87 \\
\hline L7 & 1 & 2 & 87 \\
\hline Ukupno & 6 & 7 & 412 \\
\hline
\end{tabular}

Kako se sve stanice napajaju iz različitih TS, problem preopterećenja je izbegnut. Povezivanje stanice za punjenje i TS vrši se kablovskim vodovima ukopanim u zemlju, tj. D razvodom i to primenom TN-C sistema napajanja, četvorožičnim napajanjem, tri fazna provodnika i četvrti koji ujedno predstavlja i neutralni i zaštitni provodnik.

Na slici 4 dat je prikaz TS na koje je predviđeno priključenje javnih električnih punjača na teritoriji Grbavice (uokvirene belim). Treba napomenuti da ovaj segment nije u nadležnosti projektanta, već u nadležnosti lokalnog elektro-distributivnog preduzeća, koje propisuje uslove priključenja, dimenzioniše kablove, zaštitne uređaje i ormar mernog mesta koji služe za povezivanje stanice. Kablovska i zaštitna oprema u samoj stanici za punjenje bira se na osnovu proračuna, koji je opisan u narednom poglavlju [5].

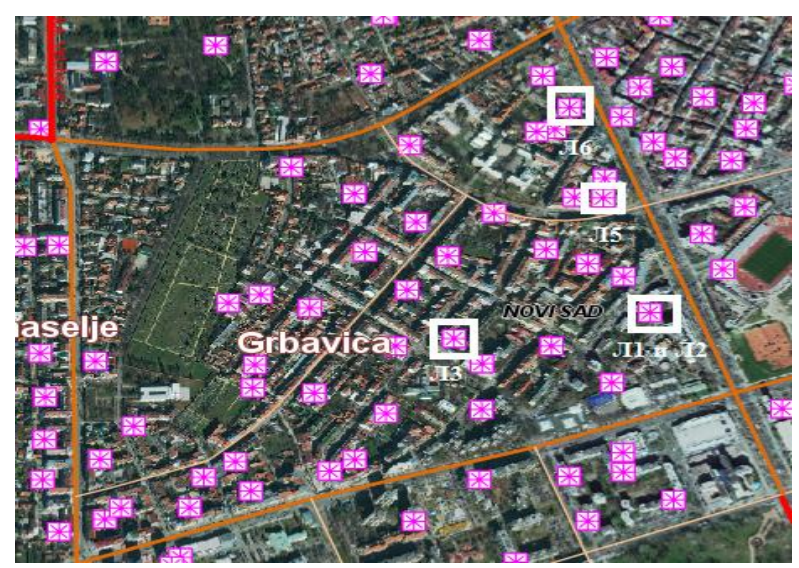

Slika 4. Prikaz TS za električne punjače na teritoriji Grbavice

\section{POVEZIVANJE JAVNIH PUNJAČA}

\subsection{Proračun elemenata}

Svi kablovi koji se koriste u stanici za punjenje određuju se na osnovu pravila propisanih standardom IEC 603645-523. Predviđeno je da su svi kablovi položeni u zemlju, a da je izolacija svakog izrađena od umreženog polietilena. Presek provodnika kabla, koji će biti korišćen mora biti u skladu sa vrednostima standarda IEC 60364-5-523, a bira se na osnovu vrednosti dobijenih proračunom. Sve proračunate vrednosti su date u tabeli 2. Radi ekonomičnosti, može se uraditi standarizacija kablova, tako da se na svim lokacijama koristiti kabl XPOO preseka $70 \mathrm{~mm}^{2}$, položen u zemlju. Ovakva standardizacija urađena je na stranu sigurnosti, s obzirom da je uzet najveći presek kabla.

Tabela 2. Brojne vrednosti pri proračunu elemenata (kablova i zaštitnih uređaja)

\begin{tabular}{|llllllll|}
\hline Zona & $\begin{array}{l}\mathbf{I}_{\mathbf{1}} \\
(\mathbf{A})\end{array}$ & $\begin{array}{l}\mathbf{I}_{\mathbf{2}} \\
(\mathbf{A})\end{array}$ & $\begin{array}{l}\mathrm{I}_{\mathbf{3}} \\
(\mathbf{A})\end{array}$ & $\begin{array}{l}\mathrm{I}_{\mathrm{TD}} \\
(\mathbf{A})\end{array}$ & $\begin{array}{l}\mathrm{I}_{\mathrm{TTD}} \\
(\mathbf{A})\end{array}$ & $\begin{array}{l}\mathbf{S} \\
\left(\mathbf{m m}^{2}\right)\end{array}$ & $\begin{array}{l}\mathrm{I}_{\text {ZAST }} \\
(\mathbf{A})\end{array}$ \\
\hline L1 & 63 & - & - & 63 & 101 & 25 & 80 \\
\hline L2 & 63 & 32 & - & 95 & 122 & 35 & 100 \\
\hline L3 & 63 & 32 & - & 95 & 122 & 35 & 100 \\
\hline L4 & - & 32 & - & 32 & 45 & 6 & 35 \\
\hline L5 & 63 & 32 & - & 95 & 122 & 35 & 100 \\
\hline L6 & 63 & 32 & 32 & 127 & 178 & 70 & 160 \\
\hline L7 & 63 & 32 & 32 & 127 & 178 & 70 & 160 \\
\hline
\end{tabular}

\subsection{Provera preseka provodnika na pad napona}

U tabeli 3 dati su ključni parametri predviđenog kabela i izvršen proraču ukupnog pada napona. Kao što se može videti, nema prekoračenja dozvoljenog pada napona, odnosno sve vrednosti su u granici od $1 \%$, tako da kablovi zadovoljavaju uslove potrošača, pad napona je zanemarljiv, pa ujedno predstavljaju i konačan odabir za povezivanje punionica sa TS na Grbavici. 
Tabela 3. Brojne vrednosti prilikom proračuna pada napona (ustanovljen poprečni pesek od $70 \mathrm{~mm}^{2}$ )

\begin{tabular}{|c|c|c|c|c|c|c|c|c|}
\hline $\begin{array}{l}\text { Zo } \\
\text { na }\end{array}$ & $\begin{array}{l}\text { I } \\
\text { (A) }\end{array}$ & $\begin{array}{l}\mathrm{S} \\
\left(\mathrm{mm}^{2}\right)\end{array}$ & $\begin{array}{l}\mathrm{r} \\
(\Omega / \mathrm{km})\end{array}$ & $\begin{array}{l}x \\
(\Omega / k m)\end{array}$ & $\begin{array}{l}\text { l } \\
\text { (m) }\end{array}$ & $\begin{array}{l}\cos \\
\varphi\end{array}$ & $\begin{array}{l}\tan \\
\varphi\end{array}$ & $\begin{array}{l}\Delta \mathrm{u} \\
(\%)\end{array}$ \\
\hline L1 & 63 & 70 & 0.15 & 0.08 & 80 & 0.95 & 0.33 & 0.36 \\
\hline L2 & 95 & 70 & 0.15 & 0.08 & 53 & 0.95 & 0.33 & 0.36 \\
\hline L3 & 95 & 70 & 0.15 & 0.08 & 33 & 0.95 & 0.33 & 0.23 \\
\hline L4 & 32 & 70 & 0.15 & 0.08 & 190 & 0.95 & 0.33 & 0.44 \\
\hline L5 & 95 & 70 & 0.15 & 0.08 & 20 & 0.95 & 0.33 & 0.14 \\
\hline L6 & 127 & 70 & 0.15 & 0.08 & 80 & 0.95 & 0.33 & 0.74 \\
\hline L7 & 127 & 70 & 0.15 & 0.08 & 85 & 0.95 & 0.33 & 0.79 \\
\hline
\end{tabular}

\section{DigSilent SIMULACIJA KVARA}

Za ovako postavljenu strukturu javnih punionica, a s obzirom na način proračuna i zadovoljene zadate kriterijume, može se zaključiti da će raditi sigurno i pouzdano. Međutim, u distributivnoj mreži može doći do pojava kvarova, bilo kratkotrajnih, bilo onih koji izazivaju kompletan ispad napajanja. U ovom radu će biti razmatrani samo oni, koji su prolaznog karaktera i koji se manifestuju pojavom propada napona na mestu priključenja punionica na mrežu. U tim slučajevima, dolazi do reagovanja zaštite i proces punjenja baterija se trajno prekida, bez obzira što je propad napona izuzetno kratko trajao (200 ms - 3 s). To predstavlja problem, pa ga je potrebno dodatno istražiti.

$\mathrm{Za}$ principijelno istraživanje postavljenog problema iskoristiće se softverski alat DigSilent, u kom je samostalno napravljen jedan hipotetički segment distributivne mreže [6]. Ovaj deo ima tri sabirnice, tri voda, na koje je povezana jedna baterija koja se puni u punionici, dva sinhrona generatora i proizvoljna dva opterećenja, što je predstavljeno na slici 5. Sistem je dimenzionisan za srednji napon od $35 \mathrm{kV}$. Simuliran je kratak spoj na vodu 1-3 i posmatran je njegov uticaj na bateriju (punjač) i sistem.

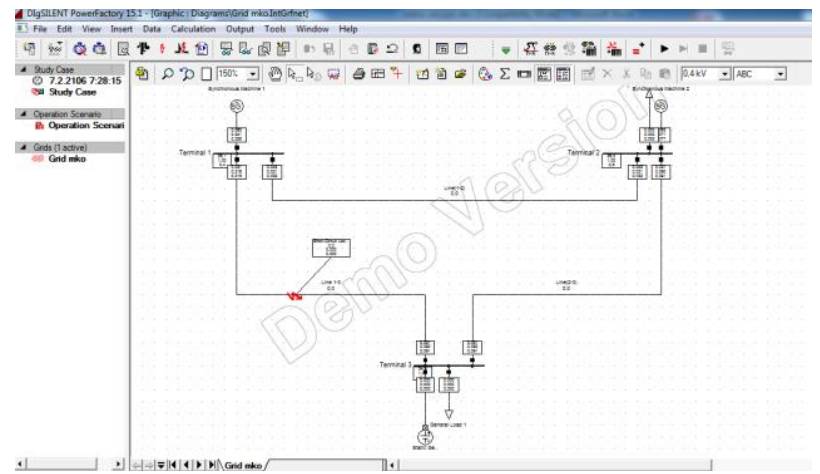

Slika 5. Prikaz sistema u DigSilent-u sa prikazanim mestom simuliranog kratkog spoja.

$\mathrm{Na}$ slici 6 prikazan je dijagram sa parametrima dvopolnog kratkog spoja sa zemljom. Pre pojave kvara, baterija (električnog vozila) punila se strujom od 0,117 kA. Prilikom pojave kvara (početak simulacije) struja je pala na nulu, što je očekivano zbog prorade zaštite koja se aktivirala u momentu prepoznavanja kvara. Vidi se da subtranzijentna snaga $\mathrm{S}_{\mathrm{k}}$, za faze a,b,c iznosi u [MVA]: $0 ; 10,55 ; 11,36$, respektivno, dok je struja kratkog spoja u subtranzijentnom periodu $\mathrm{I}_{\mathrm{k}}^{\prime \prime}$ po fazama u $\left[\mathrm{kA} /{ }^{\circ}\right]$ : $0 / 0^{\circ}$; 0,52/177,75' $0,56 / 42,44^{\circ}$, respektivno.

Može se zaključiti da pojava kvara u mreži može uticati na rad punionica, čak i ako se radi o veoma kratkim,

prolaznim kvarovima. Simulacije u softverskom alatu DigSilent pokazuju da se pojavljuju struje kvara, koje bi izazvale reagovanje zaštite ovih uređaja, odnosno došlo bi to njihovog ispada, prestanka procesa punjenja.

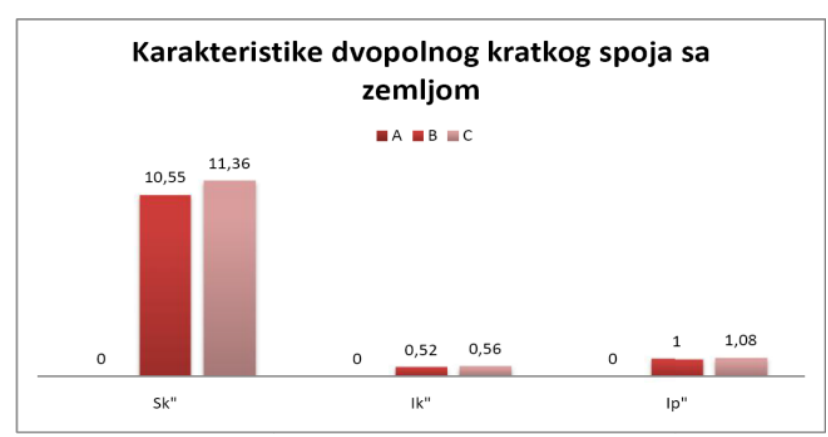

Slika 6. Dijagram struje kratkog spoja

\section{ZAKLJUČAK}

Važan preduslov za širu upotrebu električnih vozila predstavlja postavljanje široke infrastrukture punionica za baterije. Ako se one napajaju iz krovnih FN elektrana, na području Novog Sada u delu Grbavica, moguće je smanjiti potrošnju za oko $26 \%$ i za tu vrednost umanjiti emisiju $\mathrm{CO}_{2}$ u TE.

\section{LITERATURA}

[1] M.Steen, „Greenhouse Gas Emissions From Fossil Fuel Fired Power generation Systems", EUR 19754 EN, Joint Research Centre, Inst. for Advanced Materials, EC, 2000.

[2] https://pushevs.com/2016/11/23/electric-cars-rangeefficiency-comparison/

[3] J.Janković, "Urbane solarne elektrane-studija slučaja za Grbavicu u Novom Sadu”, Diplomski rad, Fakultet tehničkih nauka, Novi Sad, 2018.

[4] https://www.elektropunjaci.com/kategorijeproizvoda/javni-punjaci/

[5] D. Head, P. Kind, „Electric Vehicle Charging Station Program and Installation Guidelines“, Sonoma so, Sakramento, 2011.

[6] https://www.digsilent.de/en/

\section{Kratka biografija:}
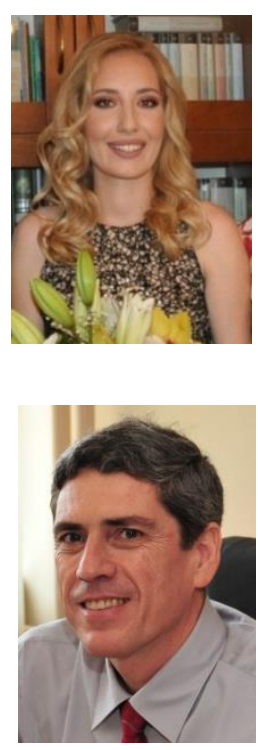

Jovana N. Janković, rođena je 20.02.1994. god. u Novom Sadu. Diplomirala je na Fakultetu tehničkih nauka u Novom Sadu 2018.godine. Upisala master studije 2018/2019 god iz oblasti Elektrotehnika i računarstvo Distribuirani elekroenergetski resursi, a master rad je odbranila jula 2019. god.

Vladimir A. Katić, rođen je 1954. god. u Novom Sadu. Diplomirao je na Fakultetu tehničkih nauka u Novom Sadu 1978. god., a magistrirao i doktorirao na Elektrotehničkom fakultetu Univerziteta u Beogradu 1981. i 1991. god., respektivno. Oblasti interesovanja su mu energetska elektronika, električna vozila, obnovljivi izvori energije i kvalitet električne energije. 